\title{
A EXPERIÊNCIA ESTÉTICA NA PRÁTICA DOCENTE DA EDUCAÇÃO BÁSICA
}

\author{
Maurício Inácio dos Santos \\ Carlos Betlinski
}

\section{Resumo}

Este artigo aborda o tema da experiência estética na prática docente. O problema condutor da investigação foi: Como os docentes da Educação Básica percebem a experiência estética em suas práticas? O objetivo foi caracterizar as experiências estéticas realizadas pelos docentes em suas práticas pedagógicas, para identificar elementos que geram o empobrecimento dessa experiência nessas práticas. A partir da análise de dados e à luz das teorias de Theodor Adorno e Max Horkheimer, afirma-se que a redescoberta do lugar da experiência estética cria sentidos e potencializa o trabalho docente, superando a tendência reducionista da racionalidade instrumental e o desencanto pela profissão.

Palavras-chave: estética; trabalho docente; racionalidade técnica.

\section{A ESTHETIC EXPERIENCE IN THE TEACHING PRACTICE OF BASIC EDUCATION}

\section{Abstract}

This paper addresses the theme of aesthetic experience in teaching practice. The problem conductor of the investigation was: How do Basic Education teachers perceive the aesthetic experience in their practice? The objective was to characterize the aesthetic experiences performed by teachers in their pedagogical practices, in order to identify elements that generate the impoverishment of this experience in these practices. Based on data analysis and in the light of Theodor Adorno and Max Horkheimer theories, it is stated that the rediscovery of the place of aesthetic experience creates meanings and enhances teaching work, overcoming the reductionist tendency of instrumental rationality and disenchantment with the profession.

Keywords: aesthetics; teaching work; technical rationality.

\section{LA EXPERIENCIA ESTÉTICA EN LA PRÁCTICA DOCENTE DE LA EDUCACIÓN BÁSICA.}

Resumen

Este artículo aborda el tema de la experiencia estética en la práctica docente. El problema conductor de la investigación fue: ¿Cómo perciben los docentes de Educación Básica la experiencia estética en sus prácticas? El objetivo fue caracterizar las experiencias estéticas realizadas por los docentes en sus prácticas pedagógicas, para identificar elementos que generan el empobrecimiento de esta experiencia en estas prácticas. A partir del análisis de datos y a la luz de las teorías de Theodor Adorno y Max Horkheimer, se afirma que el redescubrimiento del lugar de la experiencia estética crea sentidos y potencializa el trabajo docente, superando la tendencia reduccionista de la racionalidad instrumental y el desencanto por la profesión.

Palabras clave: estética; trabajo docente; racionalidad técnica. 


\section{INTRODUÇÃO}

Por prática docente, entendemos, aqui, toda ação intelectual, sensível, mediadora e intencional que envolve o ato de ensinar, no sentido de construir situações de aprendizagens. Além disso, está relacionada à ideia de formação do sujeito em todas as suas dimensões, especialmente aquelas realizadas no ambiente escolar.

Ao falar de prática docente, reconhecemos um saber-fazer do professor resultante de experiências e de sentidos atribuídos a essa prática. O professor possui saberes profissionais plurais que se revelam em suas ações cotidianas. Esses saberes são dotados de sensibilidades cultivadas ao longo de sua formação e exercício da profissão e, também, orientam seu fazer pedagógico. Nesse sentido, podemos afirmar que os docentes possuem um ofício impregnado de crenças, de conhecimentos, uma espécie de arte de ensinar que são mobilizados para os processos de formação humana.

Por meio da pesquisa, observamos, nas escolas, uma preocupação predominante com a formação de "intelectuais especialistas", uma fragmentação dos saberes e uma tendência ao desprezo de valores, como sensibilidade, afetos e subjetividade. Por força da racionalidade instrumental vinculada aos interesses de controle e adaptação social impõe-se uma educação pragmática, utilitarista, distante dos ideais humanistas de formação global que seja orientada por uma racionalidade estética.

Nesse sentido, evidencia-se a separação entre o sentir, o pensar e o agir na prática docente, que leva a uma tendência crescente de valorização dos conteúdos, habilidades e competências como forma de capacitação para o mercado de trabalho, além de um exaustivo processo de atividades burocráticas regulamentadas e medidas por notas, por conceitos, por avaliação de desempenho quantitativo. Ofusca-se, assim, a dimensão estética como fundamentação da prática pedagógica e da própria existência dos docentes e discentes.

Quando nos referimos à estética, é preciso admitir que estamos diante de um conceito que permite muitas abordagens e que pode ser tomado em vários sentidos. No contexto da pesquisa, compreendemos a estética como a dimensão da experiência sensível, capaz de produzir sensações, tocar o sujeito da experiência, deixando marcas como o conhecimento, que, em uma relação direta com os sentidos e a faculdade do entendimento, permite direcionar melhor nossas atividades e nossa existência.

Por racionalidade estética no processo pedagógico compreendemos a organização e desenvolvimento das atividades educativas considerando-se a possibilidade de mobilização da capacidade de pensar (uso da razão), afetos, emoções, sensações, criatividade e imaginação para que a experiência da aprendizagem se torne significativa e faça sentido. Essa racionalidade conjuga os sentimentos, emoções, o pensar e o fazer (ações) considerando-os como parte do processo educativo e como dimensões que se complementam e constituem as genuínas experiências de aprendizagens.

Os estudos de Adorno (1982, 2012) e de Adorno e Horkheimer (2006) apontam que o enfraquecimento dessa experiência estética é reflexo da hegemonia da razão instrumental, técnica, controladora, que se disseminou nas ciências e nas atividades sociais, entre elas a educação e a prática docente. Nesta perspectiva, o docente torna-se apenas o executor de programas curriculares, metas e planos de ensino. Faz de sua atividade um processo de autoconservação e adaptação aos esquemas e padrões de ensino pré-estabelecidos por técnicos e gestores dos sistemas educacionais.

Acreditamos, assim, que a prática docente se vê empobrecida. Atropelada pelo excesso de atividades burocráticas e técnicas, a dimensão da experiência estética do processo educativo fica 
comprometida, pois é a racionalização do tempo, o cumprimento de tarefas enfadonhas determinadas externamente que direcionam suas ações e suas decisões. Ao considerarmos esse cenário, o problema que direcionou esta investigação foi: Como os docentes da Educação Básica vivenciam a experiência estética em suas práticas pedagógicas?

O objetivo deste artigo é caracterizar as experiências estéticas realizadas pelos docentes em suas práticas pedagógicas escolares, com o intuito de identificar elementos que geram o seu empobrecimento ou a sua valorização. Partimos da hipótese de que existe uma tendência ao empobrecimento da experiência ou mesmo de negação da dimensão estética nas práticas pedagógicas, assim como, na formação dos alunos, de modo a priorizar a transferência de conteúdos, um saber predominantemente racional e técnico, como desdobramento do imperativo da racionalidade instrumental que vigora nas atividades escolares.

Orientados pelo referencial teórico de Adorno (1982, 2012) e Adorno e Horkheimer (2006) para a compreensão da experiência estética nas práticas docentes, utilizamos o conteúdo de uma pesquisa de campo que desenvolvemos junto a um grupo de docentes de duas escolas públicas localizadas no sul de Minas Gerais, que constituiu um universo de amostragem para que pudéssemos identificar o lugar da experiência estética nas práticas pedagógicas. Como procedimentos de pesquisa, aplicamos um questionário, e os dados coletados foram organizados em categorias de análise. Desse modo, foi possível identificar os pontos principais de entendimento da dimensão estética nas práticas docentes escolares, bem como fazer algumas proposições como forma de ressignificá-las e potencializar o trabalho docente.

\section{A EXPERIÊNCIA ESTÉTICA EM THEODOR ADORNO}

A palavra estética é uma palavra que vem do grego - Aesthesis, que designa percepção, sensação. Podemos compreender as experiências estéticas como todas aquelas que envolvem nossos sentidos, nossas percepções e nossas emoções. Podemos afirmar que "[...] a experiência estética está em tudo aquilo que mobiliza nossos sentidos e sentimentos, nos emociona, nos toca, nos atravessa, nos faz saber que estamos vivos” (VÁSQUEZ, 1999, p. 9).

$\mathrm{Na}$ experiência estética é aguçada a percepção, o esclarecimento, a ação livre do sujeito, permitindo o rompimento com um existir e um agir determinados pela lógica da razão instrumental, a qual se desdobra em ações utilitaristas e pragmáticas. Sobre a estética e o conhecimento, existe a compreensão de que, quando a dimensão estética está presente nos processos de ensinoaprendizagem, a relação do sujeito cognoscente com o conhecimento torna-se mais efetiva e significativa, pois a

[...] a experiência estética pode ser compreendida como a primeira forma de conhecimento do mundo. Nossas percepções sensíveis captam a realidade que nos cerca, desperta emoções e sentimentos no sujeito da percepção e também pode nos levar a outras formas de produção de conhecimentos configurados como científicos, filosóficos e artísticos. (BETLINSKI, 2016, p. 121).

Em Adorno (1982), a concepção de experiência estética é apresentada como capaz de desvincular a ação humana da lógica da racionalidade instrumental. Segundo Adorno e Horkheimer (2006), com a imposição da razão iluminista, a vida humana passou a ser dominada por uma racionalidade técnica em que tudo começou a perder o seu brilho, pois se viu curvada ao imperativo do valor econômico, pragmático e utilitarista, impondo uma dominação por meio de seu mecanismo sustentador que seria a indústria cultural, geradora de uma realidade reificada, 
produzindo a semicultura e a massificação do conhecimento, da arte, da cultura, reduzindo tudo a objeto de consumo.

No pensamento adorniano, a experiência estética aparece como força de resistência e de libertação da condição social que funciona a partir da lógica da dominação pela razão. Para Adorno (1982), na sociedade que se constituiu sobre a domínio da razão e da técnica, o sujeito acaba fazendo renúncias e enfraquecendo suas relações e suas experiências, sobretudo estéticas. Nessa perspectiva, o autor defende que, por não ter a finalidade prática e não se "enquadrar" na concepção do "servir" utilitarista e pragmático, elevando-se do mundo empírico e de suas regulações, a experiência estética pode conferir um sentido de liberdade e de ressignificação dos atos humanos.

Em Adorno (1982), encontramos a relação da experiência estética com a arte autêntica, que seria justamente aquela que não se curvou à racionalidade técnica e não se sujeitou aos ditames mercadológicos de seu valor. Ela vale em si mesma, pela capacidade de provocar emoção, reflexão, imaginação, conteúdo e capacidade de compreender a realidade social. Contudo, para Adorno (1982), a experiência estética é uma forma de conhecimento que carrega em si a capacidade de percepção da realidade. É um contraponto à lógica da razão instrumental por provocar os sentidos, aguçar o pensamento criativo, favorecer a admiração, gerar o estranhamento, criar possibilidades de pensar a realidade de inúmeras formas, de modo a contribuir para a formação humana mediada pelo entrelaçamento do sentir, do pensar e do agir.

Com Adorno (1982), aprendemos que a experiência estética supõe cultivar a atenção, o olhar, ouvir e dar-se tempo para experimentar na lentidão, na paciência e nas demoras. Requer ruptura com o estabelecido, disposição para contemplação, silêncio, abertura a transcendência presente nas fruições artísticas e em outras diversas formas de atividades humanas, como por exemplo, nas práticas pedagógicas.

A experiência estética, para Adorno (1982), é portadora da possibilidade de compreensão da estrutura cognitiva humana, como unificadora da razão e da sensibilidade, que, embora carreguem estranhamentos, são permanentemente interdependentes. $\mathrm{Na}$ sua visão, a experiência estética não é apenas emoção, mas também processo de reflexão e de conhecimento. Em conformidade com seu pensamento, Duarte Jr. (2001, p. 169) defende que "[...] o inteligível deve caminhar ao lado do sensível, o conhecer em sintonia com o sentir, por conseguinte, mesclam-se lógica e sensibilidade, razão e sentimento, conceito e estesia, num caldeirão de ideias, novas percepções, novos olhares sobre o mundo e a vida". Em outras palavras, a experiência estética confere beleza, leveza, consistência, estranhamento diante da uniformização, da quantificação e do controle da racionalidade ao existir humano.

\section{ASPECTOS METODOLÓGICOS E RESULTADOS DA PESQUISA DE CAMPO SOBRE A EXPERIÊNCIA ESTÉTICA NA PRÁTICA DOCENTE}

A pesquisa de campo ${ }^{1}$ foi realizada com 20 professores de duas escolas públicas localizadas no sul de Minas Gerais e teve como preocupações centrais a caracterização das percepções docentes correlacionadas à experiência estética na prática educativa. $O$ intuito foi identificar elementos da racionalidade técnica que causam o empobrecimento de suas respectivas práticas.

No desenvolvimento da pesquisa de campo, os docentes responderam a um questionário com 16 questões, por meio das quais eles relataram suas percepções de experiências estéticas em

\footnotetext{
1 A referida pesquisa de campo foi submetida ao Comitê de Ética da Universidade Federal de Lavras, por meio da Plataforma Brasil, que obteve aprovação com parecer favorável pelo certificado CAAE 70591317.8.0000.5148.
}

Revista Teias v. 22 •n. 67 • out./nov. $2021 \bullet$ 
sala de aula e as ações que consideram como um diferencial em suas práticas educativas. Ao mesmo tempo, eles puderam partilhar suas impressões sobre como se veem como docentes, suas dificuldades e questões relacionadas à racionalidade técnica na sala de aula. A investigação também abordou questões voltadas a experiências e metodologias diferenciadas, como o uso de música, de filmes, de dinâmicas, de brincadeiras e de outras mediações que possibilitam perceber a presença da dimensão estética no ensino e na aprendizagem. Foi possibilitada a oportunidade de expressar o que entendem por estética na educação e sua experiência de formação estética nos cursos de bacharelado ou licenciatura.

O universo de amostragem da pesquisa abrangeu as áreas de ciências humanas, exatas, ciências da natureza e linguagens e, de forma isolada, os professores de artes. O que pretendemos foi que os docentes, divididos em suas áreas, respondessem em conjunto ao questionário proposto.

Com relação aos dados do questionário aplicado aos docentes, intencionávamos perceber se eles tinham consciência do que seria o conceito e os saberes da experiência estética na educação. $\mathrm{E}$, também, independentemente dessa consciência, se suas práticas docentes revelavam um fazer pedagógico imbuído de características estéticas, bem como se a questão da racionalidade técnica influenciava predominantemente suas práticas.

Para a interpretação das respostas do questionário, foi utilizada a análise de conteúdo classificando as informações em categorias. Segundo Bardin (2011), a função primordial da análise do conteúdo é o desvendar crítico e a construção de significados. Nesse sentido, categoria é uma forma de pensamento que reflete a realidade de modo resumido em determinados momentos de um conjunto de informações ou ideias. É um procedimento que permite agrupar e classificar dados, considerando a parte comum existente entre eles, ordenados por semelhança ou analogia, segundo critérios vinculados aos objetivos da pesquisa.

Os dados foram agrupados em cinco categorias a partir de uma geral, denominada "percepção", como forma de compreender a visão sobre experiências estéticas na prática docente. Essas categorias foram nominadas de: percepção do que constitui a prática docente; percepção da influência da racionalidade técnica ou razão instrumental e seus desdobramentos na prática docente; percepção da experiência estética na prática docente; percepção da experiência da formação estética dos docentes respondentes da pesquisa; e, por fim, percepção da experiência e uso da arte na prática docente.

Para efeito de validade e importância das informações presentes nas respostas dos docentes ao questionário, foi realizado o agrupamento de pelo menos quatro respostas idênticas ou que apresentavam semelhanças, indicando uma forma de pensar dos respondentes. Tornou-se possível, assim, a construção de sentidos e de significados para o objetivo da pesquisa. Outras respostas só foram consideradas quando apresentavam relação direta ao tema e permitiam inferências com o objeto pesquisado. Não foram consideradas respostas sem sentido, que apareceram apenas uma vez e não apresentaram nenhuma informação relevante e com tendência de afastamento do objeto e foco do questionário. A seguir, discutimos cada uma das categorias.

\section{Sobre a percepção da prática docente}

A percepção do que constitui a prática docente, na visão dos respondentes, foi compreendida a partir das seguintes indagações: Como o professor descreve a prática docente hoje? O que é ser professor? Que situações dificultam o ser professor? Que situações tornam o ser professor uma profissão prazerosa? O que fortalece o trabalho docente, sobretudo em sala de aula?

$\mathrm{Na}$ análise dos dados referentes a essas questões, foram identificados certos paradoxos. Alguns docentes afirmaram ser uma experiência prazerosa, gratificante, mas, ao mesmo tempo, 
revelaram um desencanto com o ser professor. Por exemplo, o docente $A^{2}$ disse que "é uma experiência muito gratificante ser professor, pois nos realizamos quando percebemos um aluno aprendendo, mas é muito difícil ser professor com tantos problemas que a escola tem enfrentado". O docente $\mathrm{C}$ ressaltou que "ser professor é uma profissão desafiadora, cheia de altos e baixos, uma aventura extremamente burocrática e cansativa". Na visão do docente $\mathrm{F}$, o ser professor "é uma experiência marcada por muitas alegrias, mas o professor não é valorizado e reconhecido, e suas atividades são inúmeras e muito mais do que as da sala de aula, quase não tem tempo para si mesmo". Ainda nesse sentido, merece destaque a resposta do docente $\mathrm{J}$, ao apontar que, embora seja uma grande profissão, "a ação do professor fica muito condicionada a preenchimento de formulários, diários, correção de provas e outras burocracias do cargo que exerce".

Vale ressaltarmos que de 20 professores, sete usaram o termo "experiência", indicando a prática docente como uma experiência. Os demais usaram a palavra "profissão". Na sua totalidade, as respostas afirmaram que a prática docente é desafiadora e permeada por dificuldades. As principais situações desafiadoras citadas foram: baixos salários; salas numerosas; desinteresse dos alunos; indisciplina; carência de recursos pedagógicos; excesso de burocracia; falta de afetividade entre professor e aluno; a visão quantitativa da avaliação externa do Estado; excesso de atividades e de projetos, falta de tempo, entre outros. Foi possível notar que a indisciplina, falta de tempo e o excesso de burocracia foram as questões mais repetidas entre os docentes, com ênfase nas duas últimas.

Ao responderem sobre o que torna a prática docente prazerosa e fortalece o professor, a afetividade e a proximidade com o aluno sobressaiu em todas as respostas. Foi apontado também que ver o aluno progredir e se envolver na aprendizagem de forma interessada e não somente pela recompensa da nota, cria, no professor, uma motivação para o trabalho. Outras respostas também são importantes delimitadores dessa percepção sobre o que fortalece o professor, como, por exemplo, na maioria das respostas, ficou evidente que o gosto por lecionar e o interesse dos alunos motivam os professores. Ainda merecem destaques as respostas relevantes como o "brilho nos olhos dos alunos quando aprendeu alguma coisa"; "o reconhecimento dos alunos, a perseverança e a esperança diante dos desafios educacionais", dito pelos professores J e F, respectivamente.

$\mathrm{Na}$ visão do docente $\mathrm{A}$, "estar próximo do aluno e conviver com ele diariamente fortalece a prática educativa, mesmo com tantos alunos e pouco tempo na sala de aula". Ele ainda destacou que "sem afeto e respeito pelo aluno a profissão do professor não tem sentido". O docente E ressaltou que "a maior motivação para um professor é ver que seu aluno está aprendendo e crescendo com o que está sendo ensinado". Por sua vez, o docente G fez uma afirmação com as seguintes palavras: "Me sinto motivado quando vejo interesse nos alunos e me empolgo com as aulas".

O conjunto dessas respostas, quanto à percepção do docente de si mesmo, sugere que os docentes vivem uma dicotomia entre encanto e desencanto, em uma situação de desânimo com seu ofício. Esse desencanto deve ser associado ao excesso de atividades burocráticas na sala de aula e ao fato de verem pouco progresso em suas práticas no que diz respeito à aprendizagem dos estudantes. As respostas revelam que os docentes não têm tempo e que esse fato traz cansaço e dificulta a aproximação e a convivência com os alunos. Nesse sentido, o tempo para fazer experiência é substituído pela necessidade de "transmitir conteúdos", aplicar avaliações, corrigir atividades, "fechar notas" e controlar a indisciplina, em salas de aulas quase sempre numerosas.

\footnotetext{
2 Por razões éticas e para preservar a identidade dos professores que responderam ao questionário, não foi apresentado o nome de cada respondente. Por isso, foram usadas a expressão docente ou professor A, B, C, D, E, F e assim sucessivamente.
} 
Uma percepção que destacamos ao término deste tópico é a dificuldade dos docentes de narrarem suas atividades e suas experiências. Isso foi constatado a partir da identificação de respostas curtas, ideias contraditórias e confusas em alguns momentos e, em outros, ausência de narrativas sobre suas práticas, limitando-se a estereótipos ou clichês que são corriqueiros para traduzir a prática docente. Esse fato pode revelar uma resistência ao instrumento da pesquisa, em uma atitude negativa de insegurança de se expor ou, ainda, uma questão mais séria e problemática: um estado psicológico de emudecimento dos docentes diante de tantos desencantos presentes no cotidiano escolar. Por isso, resistem em narrar suas práticas, pois elas não se revelam como experiências que têm sentidos para eles.

\section{Sobre a percepção da influência da racionalidade técnica na prática docente}

Quanto à percepção da influência da racionalidade técnica ou da razão instrumental e seus desdobramentos na prática docente, partimos de algumas perguntas bem específicas. Questionamos o que deveria ser prioridade na prática docente: a razão, os conteúdos, a emoção, a sensibilidade, a técnica, o afeto ou outros aspectos. Os livros didáticos e as apostilas são os melhores recursos para a condução das aulas? Eles garantem a padronização e a eficiência do ensino? A atividade de ensinar é racional, sensível e criativa? O que deve predominar? $\mathrm{O}$ que significa uma prática docente inovadora?

Todas as respostas apontaram que, hoje, se prioriza o racional, o conteúdo, e algumas respostas ainda complementaram que o cumprimento do currículo e a exigência de resultados expressos pelas notas das provas durantes os bimestres e as avaliações externas do governo sobrepõem-se a tudo. Para o docente I, "a escola hoje foca muito nos resultados a partir das notas dos alunos, na quantidade de aprovados no fim do ano". Já o docente E lembrou um aspecto questionador importante ao afirmar que "o cumprimento do currículo é uma norma das escolas e que os resultados nem sempre correspondem à realidade, pois, no fim, todos têm que passar". O docente J afirmou que, em sua opinião, "a escola prioriza mais o racional, os conteúdos e que há um exagero na ideia de preparar para vestibular e Enem e que não deveria ser assim". "Para a escola, o que importa é o conteúdo e no final as provas têm que demonstrar o que foi dado ao aluno e como ele aprendeu ou não", destacou o docente B.

Como contraposição à questão da predominância de um ensino orientado pela racionalidade técnica nas práticas docentes, todos afirmaram que a sensibilidade deveria ser valorizada. No entanto, ao narrarem suas práticas inovadoras, é possível perceber que há uma prevalência de aulas que priorizam os conteúdos, a questão da cidadania, as atividades racionais, o uso de tecnologias, com exceção da disciplina de artes. Para todos os professores, quando se trata de conteúdo ligado a valores, as questões do sensível são mais fáceis de ser trabalhadas. Na resposta do docente $G$, "deve haver equilíbrio entre o conteúdo, a razão e outras áreas e a formação humana também deve ser uma preocupação para educação". Uma resposta chama atenção quando o docente C fez a seguinte afirmação: "Todos são importantes, mas a razão deve ter destaque, pois estamos formando cidadãos responsáveis e de bem". Outra resposta do docente A merece ser ressaltada quando o docente afirmou que "deve haver um complemento entre elas para moldar o profissional completo".

Entre as respostas, seis defenderam a união entre o racional e o sensível, mas com uma conclusão intrigante do docente F, ao afirmar que "estamos preparando os alunos para situações diversas do mercado de trabalho", ou do docente E, que destacou "ajuda na disciplina e no manejo da sala de aula".

Ainda assim, sobre práticas inovadoras, as respostas são diversas: diálogo entre professores 
e alunos; não apenas conteudismo; fugir das metodologias clássicas; uso das artes; despertar curiosidade; ouvir e fazer o aluno ativo no processo de aprendizagem; diversidade de recursos tecnológicos e metodológicos. Há uma coincidência nas falas de diversos docentes como, por exemplo, G, B, F e J, praticamente com a mesma afirmação ou grande semelhança, ao responderem que "o professor não pode ficar só nas aulas tradicionais, tem que envolver o aluno, diversificar na hora de ensinar, ouvir, dialogar e conviver com os alunos". Os professores A, I e F apresentaram a mesma afirmação com os dizeres: "Os recursos tecnológicos despertam interesse no aluno e prende a atenção deles".

O uso de livros didáticos, apostilas e outros materiais foram apontados como forma de despertar o interesse dos alunos e os aproximarem dos conteúdos, evitando a dispersão. Contudo, foi unânime que esses recursos levam à padronização, mas não garantem a eficiência. $\mathrm{Na}$ visão do docente $\mathrm{H}$, "sem o livro didático não teríamos acesso a nenhum material, mas a padronização com esses materiais nem sempre garante uma boa educação". O docente B afirmou que "o livro didático nos auxilia na explicação teórica dos conteúdos, mas não podemos ficar somente neles". Um grupo de docentes, os docentes, $\mathrm{C}, \mathrm{H}$, I e J são da mesma opinião de que "os livros didáticos nem sempre correspondem a nossa realidade e precisam ser completados com outros materiais".

A expressão "deve haver equilíbrio entre racional, sensível e criatividade" apareceu na totalidade das respostas. Todavia, sempre havia uma ênfase no sentido de que é necessário preparar o aluno; deve ter cuidado para não perder o objetivo de vista; o aluno precisa de conteúdo; é bom para ajudar na questão da disciplina e despertar interesse. Segundo o docente D, "conteúdo, emoção e razão devem andar juntas para uma boa formação dos alunos". Outros docentes, como, por exemplo, B, H e G, fizeram afirmações que se aproximam, ao responderem que "trabalhar o racional e o sensível auxiliam na disciplina, desde que o conteúdo curricular não seja prejudicado". O docente $\mathrm{C}$ usou uma ênfase com a seguinte fala: "Desde que o racional não fique prejudicado, todas as iniciativas são importantes".

Não houve nenhuma referência à expressão criativa, a não ser de forma indireta quando muitos afirmaram que uma aula precisa ser diversificada para "prender" a atenção dos alunos. Há afirmações de que o professor precisa ter afeto para ter a confiança do aluno. $\mathrm{Na}$ expressão do docente A, "uma aula diversificada e interessante tem que usar uma técnica que prende o aluno e ajuda na aprendizagem". Na mesma linha, o docente $\mathrm{F}$ argumentou que "as aulas precisam ser diversificadas para que o aluno tenha interesse e que tenha disciplina na sala de aula". Em outra resposta, o docente $G$ destacou que "conquistar o afeto do aluno e sua confiança é o primeiro passo para uma aula diferente e uma boa dinâmica para que o aluno tenha interesse".

Quatro respostas chamaram atenção ao abordar a questão do trabalho com a sensibilidade e a criatividade na sala de aula. É uma situação que exige tempo e preparação do professor e, diante das atividades rotineiras de cumprimento dos conteúdos, o planejamento burocrático e os diversos projetos escolares não abrem espaço para um trabalho diferenciado nessa área. Como exemplo desse pensamento, o docente I assinalou, em uma de suas respostas: "O professor tem tanta coisa para trabalhar durante as aulas que nem sobra tempo para outros aspectos, e a sensibilidade e a criatividade exigem que o professor esteja preparado". Diante dessas respostas, observamos que a educação escolar tende a ser guiada pela questão da racionalidade instrumental. Essa racionalidade está presente e evidenciada na transmissão de conteúdos, nas notas, nas avaliações e no controle do tempo, como forma de garantir eficiência, precisão e igualdade nas práticas escolares.

As práticas docentes estão influenciadas pela racionalidade técnica, ainda que eles tenham consciência da importância da sensibilidade. O cumprimento do currículo e a necessidade de ter uma lógica na apresentação dos estudos e conteúdos acabam sendo impostos aos docentes como uma norma do sistema educacional, servindo também como padrão de rendimento, um meio de 
não se perder na sucessão de assuntos e de matérias a serem ensinadas, tornando o livro didático e as apostilas os recursos técnicos mais usados, ainda que, na afirmação dos respondentes da pesquisa, eles não sejam a garantia de eficiência, além de ignorar a diversidade e os estilos subjetivos de aprendizagem dos estudantes.

A aula inovadora é vista como consequência do uso de recursos diversos, atividades diferenciadas, não como um momento de experiência, de encontro. A maneira de repassar o conteúdo de forma dinâmica seria por meio do uso de computadores, de filmes, de Datashow ou outro recurso que seja capaz de atrair a atenção dos alunos. A questão da racionalidade técnica é subjacente nessas respostas com o entendimento de que a técnica é o melhor caminho para tornar o aprendizado mais atrativo, independentemente das relações afetivas e das experiências a serem construídas com esses recursos.

\section{Sobre a percepção da experiência estética na prática docente}

Em relação à percepção da experiência estética na prática docente foram feitos os seguintes questionamentos: O que o docente entende por uma aula alegre e diferenciada? O que pode tornar uma aula prazerosa? Que sentimentos procura despertar nos alunos durante a aula? Que experiências de alegria e de prazer já vivenciou ou vivencia com os alunos? O que é mais importante na hora da aula, a razão ou a sensibilidade? Você acredita que a experiência estética na educação pode valorizar o trabalho docente? Em sua opinião, como a escola poderia valorizar a dimensão da experiência estética em seu cotidiano? O que é estética?

As respostas dos professores permitem diversas percepções sobre experiência estética. Quanto à aula alegre, diferenciada, prazerosa e os sentimentos despertados nos alunos, as respostas mais comuns foram quando há momentos de alegria, de diálogo com os alunos, de convivência, de interesse; admiração, curiosidade, quando a ciência se aproxima da vida dos alunos; uma aula diversificada de recursos; quando o aluno compreende o que está estudando; quando os alunos se divertem com o conhecimento; quando o sensível é tocado. Segundo o docente A, "uma aula é boa quando os alunos se envolvem, tem curiosidade e que os conteúdos se aproximam dos alunos". Para o docente C, "se o professor é capaz de usar recursos diversificados e dialogar com os alunos isso desperta interesse e admiração dos alunos". O docente F destacou que "convivendo com os alunos e dialogando com eles é possível despertar a dedicação e a emoção do aluno na hora de estudar".

A ênfase na curiosidade e o compromisso com os estudos é o que mais procura ser despertado pelos professores nos alunos. O carinho, o respeito, a amizade e a admiração foram destacados por alguns professores como sentimentos importantes, aqui relacionados à expressão "formação do aluno". $\mathrm{Na}$ resposta do docente $\mathrm{J}$, foi destacado que "temos que despertar sentimento de compromisso e curiosidade nos alunos para que possam gostar de estudar", e o docente D destacou: "Para formar o aluno é necessário o respeito, ter carinho e amizade na sala e também admiração como forma de estimular o aluno".

O termo "utilidade" apareceu de forma curiosa em quatro respostas com variações diferentes, mas sempre ligado à expressão destacada por docentes e modos diferentes, ressaltando que é preciso "despertar o sentimento de importância da utilidade do que está sendo ensinado para a vida dos alunos", disse o docente I, ou, ainda, "despertar o gosto pela disciplina e ou matéria que está sendo estudada porque ela será importante na etapa seguinte ou para a prova ou concurso e Enem", afirmou o docente F.

No aspecto da estética, diferentemente da abordagem da questão semelhante anterior, todos afirmaram que a sensibilidade deve ser prioridade nas aulas e que o racional é importante e 
não deve ser separado da questão dos valores como afeto, respeito, emoção, diálogo, beleza. Por exemplo, a seguinte afirmação do docente B pode ser destacada: "A razão é importante e a base do conhecimento, mas o aluno precisa também aprender a desenvolver o sentimento e a emoção que deve fazer parte de nossa vida".

Todas as respostas coincidiram com a ideia de que a estética está ligada ao belo, mas alguns afirmaram não saber definir o que é estética e que necessitaram pesquisar sobre o tema. Muitos a relacionaram ao lúdico, à alegria, à sensação, à emoção, à intuição e até a questão de aparência. Outros a definiram como uma disciplina que deveria existir na escola para contribuir para a formação sensível dos alunos. O docente I destacou que "a estética é tudo que envolve a alegria, o que é bonito, a questão da aparência"; e o docente G associou a estética como apenas uma disciplina que deveria haver na escola ao afirmar que ela "deveria existir na escola para ajudar o aluno e o professor a desenvolverem a questão da sensibilidade". Outra resposta, a do docente D, relacionou a estética a "uma forma de trabalhar o lúdico, desenvolver a sensação e capacidade de intuição e emoção".

Algumas respostas apontaram para a ideia de que a estética é convivência e postura profissional dos professores com o aluno no momento da aula quando há respeito, afeto, diálogo. Em algumas respostas, houve associações da estética com o campo da arte; e outras se aproximaram mais da definição de ética. A questão do modo de se vestir, da cultura e das diferenças foram destacadas por alguns professores com aspectos relacionados à estética. Outros ligaram a estética a uma metodologia para despertar a sensibilidade e que ela estaria ligada às artes como músicas, filmes, esculturas, quadros, entre outros. Para o docente C, "a estética está presente em todo o momento da escola e envolve desde a relação com o aluno e com outros profissionais". "Quando a escola valoriza a cultura e a diferença está trabalhando a estética", destacou o docente $\mathrm{B}$ em sua resposta; e, na visão do docente F, "o saber conviver, o diálogo e alegria na sala de aula está relacionada à estética".

Quando indagados se a escola valoriza a experiência estética em seu cotidiano, houve divergências entre as respostas. Para uns sim, para outros não, e alguns afirmaram que, em parte, a escola valoriza a estética em alguns momentos específicos, como nos projetos culturais, nas festas ou quando o professor utiliza músicas, filmes e outros recursos. $\mathrm{Na}$ resposta do docente $\mathrm{H}$, "a escola valoriza constantemente a estética através de projetos e quando incentiva o trabalho de temas transversais em sala de aula”. Para o docente F, "a estética é trabalhada em sala através de músicas, filmes, poemas ou quando um professor usa um recurso que não seja apenas conteudista". Já o docente A foi incisivo ao afirmar que "a escola nem sempre valoriza a questão estética, o foco mesmo é a questão da formação técnica, para o mercado de trabalho".

Todos os docentes afirmaram que a escola poderia valorizar mais a questão estética, mas não indicaram de que forma deveria acontecer essa valorização, apenas disseram que a escola deveria: dar mais formação aos professores; dar autonomia na sala de aula; promover debates na escola e com a comunidade; trabalhar as diferenças; valorizar a cultura e a arte; valorizar os estilos dos alunos; identificar os professores que trabalham com estética em sala e valorizar essas experiências. Uma resposta curiosa foi dada pelo docente D: "diminuindo o aspecto prisional da sala de aula".

Quanto ao fortalecimento e à potencialização do trabalho docente, a partir da experiência estética, as repostas ao questionário foram assertivas. Todos concordaram que a estética, na sala de aula, pode fortalecer o trabalho docente, mas as abordagens são diversas: "transvaloriza" o trabalho do professor; desperta no professor a sensibilidade; só vale se agregada a outros princípios como a ética; ajuda a despertar o interesse dos alunos e a controlar a indisciplina; contribui para a diversidade e o respeito às diferenças; ajuda, pois o sistema valoriza mais o quantitativo; torna a 
aula diferente e alegre. Para o docente I, "o trabalho com estética poderia fortalecer as aulas e ajudar os alunos na questão da disciplina". Segundo o docente J, "a estética dentro da escola seria uma oportunidade de trabalhar a diversidade e o respeito, mas o sistema valoriza mais o quantitativo". Outra resposta aparece como reforçadora de um pensamento coletivo, a do docente B, ao afirmar que "a estética pode propiciar uma aula alegre e diferente, mas tem que estar ligada à formação profissional e à ética”.

Ao levarmos em consideração as respostas sobre a percepção da experiência estética na prática docente, é possível percebermos que há certo estranhamento e confusão teórico-conceitual por parte daqueles que não são chamados "especialistas" em arte ou aqueles que trabalham diretamente com o conteúdo das artes. Há um olhar de desconfiança para um conhecimento que parece pertencer a alguns e que não é visto como tão importante quanto as áreas disciplinares mais "nobres" do currículo escolar, e até consideradas "mais úteis" para a formação do aluno.

A experiência estética está presente na prática docente, porém muitos a concebem como algo secundário, uma disciplina a parte a ser ensinada ou, ainda, uma metodologia para tornar a aula diferenciada e atrativa, bem como nos apelos da indústria cultural como estratégia de criar e despertar o interesse. Nesse sentido, ela não é concebida como uma práxis constitutiva da prática docente, algo que deva ser intrínseco ao pensar, agir e sentir presentes nos processos educativos escolares.

\section{Sobre a percepção da experiência estética na formação dos docentes}

A percepção da experiência estética dos docentes durante sua formação envolveu os questionamentos alusivos aos tempos de Graduação e de prática profissional: Ao longo de sua formação profissional, como você identificaria a formação estética? Como você realiza experiências estéticas em sua vida profissional?

Nas respostas sobre a formação estética docente, a maioria dos respondentes afirmou que não receberam nenhuma formação específica nesse campo durante a Graduação, seja licenciatura ou bacharelado. Algumas respostas indicam que o tema nem mesmo era tratado de forma indireta ou interdisciplinar na Graduação. As exceções aparecem nas respostas do professor de Artes, que identificou toda a sua formação em sintonia com a questão estética. $\mathrm{Na}$ resposta dos docentes, a afirmação comum foi "durante a minha formação na faculdade não foi tratado deste tema", e as respostas de outros docentes, como, por exemplo, A, B, D e J coincidiram ao apontarem que "a questão da estética só foi mencionada nas aulas de filosofia".

Em algumas respostas, foram encontradas as seguintes afirmações: Docente A, B e G: "nunca ouvi falar em formação estética para os professores de outras disciplinas que não fosse Artes"; docentes H e J: "a estética não faz parte da formação do professor nas faculdades", "priorizava-se mais a formação profissional"; docentes D e E: "só ouvi falar em estética quando estudei filosofia na faculdade"; docentes C, D e F: "a formação era mais conteudista da formação específica do professor".

A maioria dos docentes respondeu que procuram viver e realizar a questão da estética em sala de aula usando momentos de descontração, músicas, filmes. Em outras respostas, a afirmações do uso do diálogo, do respeito e do desenvolvimento de uma aula diferenciada e alegre.

Todas as respostas apontam que a estética é importante para a relação professor e aluno, associada a questões do ensino e da aprendizagem e do controle da disciplina. Para uns, a estética contribui para a construção de valores e o respeito ao outro. Na resposta do docente G, "a estética na sala de aula é uma grande oportunidade para desenvolver valores e atitudes de respeito"; e outra, do docente A, "a estética na sala de aula aproxima professor e aluno e contribui para a 
aprendizagem". Repetidamente, uma resposta, a do docente D, associou a estética na sala com o controle de disciplina ao afirmar que "a estética ajudando na questão da boa convivência e da sensibilidade pode facilitar a boa convivência e a organização da sala de aula".

A partir dessas evidências, podemos afirmar que a estética não faz parte da formação dos professores, ao menos nas respostas desses docentes. Com exceção do professor de artes, os demais demonstraram um estranhamento ao tema, conforme se percebe no conjunto das respostas apresentadas. A preocupação com a formação específica na área profissional ou talvez o não entendimento da experiência estética como uma dimensão da educação faz com que os futuros docentes não tenham um aporte teórico e conceitual que possa iluminar suas práticas, criando uma convicção que possa orientar suas experiências profissionais.

Ainda assim, mais da metade dos docentes identificaram momentos de experiência estética no seu cotidiano, sobretudo nos momentos de relação com o aluno, indicando que, embora não tenham uma formação ou construção do conceito de estética ou que este seja associado de modo confuso à questão de aparência ou mesmo de valores e estratégicas metodológicas de ensino, suas práticas são fortalecidas por essa experiência e criam um diferencial para elas. Uma resposta do docente J ilustra de maneira clara esse entendimento ao afirmar que "experimentamos a estética quando conseguimos despertar a alegria e a emoção durante as aulas e quando são trabalhados os valores que ajudam na convivência dos alunos".

\section{Sobre a percepção da experiência estética a partir do uso da arte na prática docente}

Por fim, a percepção da experiência estética a partir do uso de recursos artísticos na prática docente propôs o questionamento sobre o uso de filmes, de imagens, de músicas, de danças, de dinâmicas e de outras experiências, e como os docentes percebem os alunos quando utilizam essas experiências na relação ensino e aprendizagem. Além desse questionamento, foi proposto aos docentes que apresentassem seu entendimento sobre a seguinte afirmação: "O trabalho do professor é uma arte e a prática docente precisa ter um sentido estético".

A metade dos docentes indicou que fazem uso de filmes e de músicas em suas aulas. Outros responderam que não empregam nenhum recurso, mas defendem sua importância para auxiliar na aprendizagem. As respostas foram associadas a uma aula diferenciada, prazerosa e que desperta interesse. Também pudemos encontrar nas respostas o uso de filmes e de músicas para descontrair os alunos e controlar a disciplina. Apenas três respostas aparecem associadas à questão da aprendizagem. Para o docente A, "o uso de filmes contribui para uma maior assimilação dos conteúdos e maior interesse nas aulas". Outra resposta, a do docente J, afirmou que "a aula fica mais descontraída e os alunos mais concentrados e envolvidos". Em um terceiro exemplo, o docente $\mathrm{H}$ respondeu relacionando a questão do ensino e da aprendizagem à seguinte afirmação: "O uso de uma metodologia diversificada de filmes e músicas pode facilitar a compreensão dos temas que estão sendo estudados". Alguns docentes, como, por exemplo, B, D, F e I, apresentaram respostas semelhantes com os dizeres, "não faço o uso de vídeos e outros recursos por questão de tempo e recursos".

A questão do uso de imagens, de dinâmicas e de danças apareceram apenas nas respostas dos professores de Artes, associada à aprendizagem, à imaginação e à criatividade. O docente das artes, na sua resposta, associou sua prática ao emprego desses recursos como atividades formativas, mas em determinadas respostas associou essas práticas como forma de completar os conteúdos ou estimular o interesse pela disciplina.

Quanto à opinião sobre a docência como arte e o sentido estético da atividade educativa, as respostas foram diversas e algumas contraditórias ou mesmo negativas. Três respostas, docentes 
B, H e I, não souberam como essa questão se relaciona com o professor. Entretanto, na maioria das respostas, há pontos de consenso ao afirmarem que o professor deve buscar a beleza, educar de forma lúdica, se preocupar como tornar a aula interessante para os alunos, não só ensinar conteúdos, mas valores e sentimentos. Nas respostas dos docentes, podem ser destacadas várias afirmações, como, por exemplo, a do docente A: "A arte é transcendência do ser, eleva o homem, ensinar é evoluir, o professor cria e dá beleza a sua criação"; a do docente G: "A arte é uma forma estética e lúdica de educar"; a do docente F: "A educação é uma a arte de ensinar e aprender". $\mathrm{Na}$ opinião de outro docente, "o professor é um grande artista que desperta no aluno o gosto por saber e aprender, mas tem que equilibrar sua prática na estética com outros conhecimentos" (Docente D).

Algumas respostas associaram a questão do professor a ser uma vocação e missão na arte de ensinar. Ele aguça o sentimento nos alunos e o papel de um grande artista é despertar o gosto por alguma coisa; no caso do professor, o gosto pelo saber e aprender. Determinadas respostas apontam para o docente como artista no sentido de ter a oportunidade de trabalhar com a estética em sala de aula e que sua missão é equilibrar ética e estética. Para o docente C, "o professor deve ser como um artista e usar sua criatividade para criar situações interessantes na hora de ensinar". O docente F fez a seguinte afirmação: "Professor é profissão e missão, é preciso ter dom, criatividade e sensibilidade com o que faz".

Ao considerarmos as respostas sobre o docente como artista e o sentido estético da sua prática, pudemos notar que os respondentes da pesquisa têm uma visão associada prioritariamente à questão do ensino de artes ou como recurso complementar. Em uma das respostas, o docente $\mathrm{A}$ fez alusão a essa percepção ao afirmar que "a estética e a arte podem ser um meio de melhorar a dinâmica da sala de aula". Mais uma vez prevaleceu a ideia de arte e de estética como estratégia metodológica de ensino e de aprendizagem e não como uma dimensão da educação ou força potencializadora das práticas docentes.

Há, de certo modo, reflexos nítidos de uma concepção de arte e estética no sentido utilitarista, sempre em função de alguma coisa, para cumprir uma finalidade, fazer mediação em uma determinada situação. A estética, como o estado humano do sentir, não é colocada como fundamental em relação ao pensar e ao agir.

O uso de filmes e de músicas como uma forma de entretenimento - justificada como uma forma de tornar a aula mais atrativa e evitar a indisciplina, como recurso complementar ao "programa" de ensino e para ampliar o entendimento do conteúdo - é evidência de que essas práticas estão vinculadas à influência da indústria cultural. Além disso, chama atenção uma afirmação de que, em uma escola, usam-se filmes para substituir a ausência de professores. Em uma resposta, o docente $\mathrm{G}$ afirmou: "Em minha escola, poucos são os professores que usam filmes e, quando usam, não tem a ver com a questão que está sendo ensinada". O docente $C$ ainda destacou: "Na maioria das vezes, o filme serve para atividade de substituição de um professor faltoso".

\section{O LUGAR DA EXPERIÊNCIA ESTÉTICA NA PRÁTICA DOCENTE}

Os múltiplos olhares para a prática docente observados na pesquisa de campo retratam que a experiência estética está presente no cotidiano escolar, mesmo com a predominância da racionalidade técnica. A perspectiva da experiência estética, capaz de potencializar e dar sentido ao trabalho do professor, de modo especial na Educação Básica, como forma de promover a união do sentir, do pensar e do agir, mesmo em condições sociais profundamente utilitaristas e 
pragmáticas, mantém-se apenas latente.

Consideramos que a experiência estética não pode estar dissociada da educação e das práticas docentes, pois ela contrapõe-se à lógica discursiva e às ações que reforçam a ideia de que a escola e o professor devem priorizar a formação técnica, habilidades para o trabalho competitivo. $\mathrm{Na}$ lógica desse discurso, ao docente e ao aluno, não são facultados uma experiência estética, que são substituídas pela "desilusão oficial" e "total fidelidade" ao sistema, gerando passividade, desencantamento e resignação (FERREIRA; FRANÇA; VIEIRA, 2016).

Adorno (1982), em suas reflexões, aborda a experiência estética como força constituidora do pensamento, que, na prática docente, pode inspirar os educadores a pensar na importância da esteticidade do pedagógico, na experiência estética. Ao discutir a dimensão estética na prática pedagógica, Pagni (2007), ao considerar o pensamento de Adorno, destaca que, mediado pela experiência estética, o cotidiano escolar pode ser espaço transformador e sensível para a prática docente, representando uma ruptura com o modelo da racionalidade técnica.

A prática docente orientada pela racionalidade estética representa uma grande possibilidade de inovação, pois:

É preciso ousar, no sentido pleno desta palavra, para falar em amor sem temer ser chamado de piegas, de meloso, de a-científico, senão de anticientífico. É preciso ousar para dizer cientificamente que estudamos, aprendemos, ensinamos, conhecemos com nosso corpo inteiro. Com sentimentos, com as emoções, com os desejos, com os medos, com as dúvidas, com a paixão e também com a razão crítica. Jamais com esta apenas. É preciso ousar para jamais dicotomizar o cognitivo do emocional. (FREIRE, 1993, p. 10).

Por isso, a experiência estética pode ressignificar as práticas docentes e fazer parte da vida pessoal e profissional - desde a formação inicial, a ser experimentada em todos os momentos das atividades educativas escolares. Duarte Jr. (2001) corrobora a compreensão de que, ao ser fortalecido pela experiência estética, cada professor pode se inspirar, imaginar e criar situações de contato com o conteúdo sensível por meio de filmes, de músicas, de imagens, de expressão corporal, de diferentes formas de expressões de afeto e de emoção, dentre outras atividades que poderão contribuir para a ampliação da formação cultural e da sensibilidade. Consequentemente, essas práticas contribuirão para os processos formativos docentes, criando oportunidades de experiências significativas a serem narradas e transmitidas àqueles que compartilham o ofício de educadores.

Se, para Adorno (2012), experiência estética é um caminho possível para a construção da autonomia tanto da arte quanto do sujeito, podemos pensar que essa experiência tem um lugar especial na prática docente como forma de potencializá-la. Como na arte autêntica, não sujeitada, essa prática pela experiência estética pode se desprender das amarras da racionalidade instrumental, reinventar-se de maneira criativa, construir seu próprio caminho, inclusive para a autonomia.

Nessa perspectiva, Hermann (2006) diz que a experiência estética pode representar uma reorientação para novas práticas docentes, movidas pela sensibilidade, pelo afeto, pelas emoções, capazes de contagiar a racionalidade, dando a ela uma dimensão estética. Se o cotidiano é entrecortado por adversidades que tendem a limitar a prática docente, a experiência estética pode desencadear uma ação emancipadora, tanto do docente como do aluno, capaz de mobilizar um processo de ensino e de aprendizagem de forma positiva, prazerosa e motivadora. Nesse sentido, permitem entender as relações formativas como processos de produção de sentidos, verdadeiros encontros entre pessoas, que prezam pela qualidade das relações entre professor e aluno que vão muito além das imposições da racionalidade técnica. 


\section{CONSIDERAÇÕES FINAIS}

Na abordagem do tema da experiência estética nas práticas docentes, evidenciamos que elas estão permeadas por saberes sensíveis e artísticos. Entretanto, percebemos que o maior desafio dos educadores é superar o paradigma da racionalidade instrumental expressa no pragmatismo e no tecnicismo pedagógico.

Estética pode ser compreendida como a faculdade humana da percepção sensória, que articula a cultura com as individualidades, de modo a criar representações, emoções e sentidos que nos são próprios, unindo a razão e a corporeidade, o sentir, o conhecer, o agir, como expressões dos processos educativos. Não se trata de uma visão de estetização ingênua da prática docente, em meio a uma sociedade neoliberal utilitarista, mas da defesa de um lugar para a experiência estética como modo de significá-la e potencializá-la. Se, por um lado, é possível perceber que um dos principais problemas que afetam a educação e a prática docente é a falta de vitalidade dos processos de formação, sobretudo quando se veem atrelados a um discurso e a uma prática que se realiza exageradamente no plano racional e técnico; por outro, as práticas docentes que transcendem esse discurso reducionista se reinventam, encontram motivações e força para vencer os desafios inerentes ao cotidiano escolar.

A pesquisa de campo evidenciou que, a seu modo, muitos docentes praticam atividades relacionadas ao campo da estética, apesar de muitas estarem sob a influência da concepção reprodutivista da indústria cultural ou representarem mais uma estratégia de ensino do que propriamente uma experiência estética no sentido proposto pela pesquisa. As tantas possibilidades de experiências estéticas, conscientes ou não, planejadas ou espontâneas, escapam a um enquadramento teórico acadêmico único e sinalizam para a pluralidade de caminhos que marcam o ofício docente. Assim concebida, a experiência estética potencializa o encantamento e o entusiasmo pelo trabalho pedagógico, conferindo-lhe um sentido emancipatório.

\section{REFERENNCIAS}

ADORNO, Theodor. Teoria estética. Trad. Artur Morão. Lisboa: Edições 70, 1982.

ADORNO, Theodor; HORKHEIMER, Max. Dialética do esclarecimento: fragmentos filosóficos. Trad. Guido Antônio de Almeida. Rio de Janeiro: Jorge Zahar, 2006.

ADORNO, Theodor. Educação e Emancipação. Trad. Wolfgang Leo Maar. 4. ed. São Paulo: Paz e Terra, 2012.

BARDIN, Laurence. Análise de conteúdo. Lisboa, Portugal: Edições 70, 2011.

BETLINSKI, Carlos. Notas sobre cinema e experiência de formação estética. In: PUCCI, Bruno. et. al. A atualidade da Teoria Crítica na era global. São Paulo: Nankin, 2016.

DUARTE JR., João Francisco. Fundamentos estéticos da educação. 6. ed. Campinas: Papirus, 2001.

FERREIRA, Luciana Haddad; FRANÇA, Raul Cabral; VIEIRA, Beatriz Vito. Estética do cotidiano: experiência e produção de saberes na formação docente. Espaço Pedagógico, Passo Fundo. v.(23), n.( 1), p.(83-98), jan./jun. 2016.

FREIRE, Paulo. Política e Educação. São Paulo: Cortez, 1993.

HERMANN, Nadja. Educação e Racionalidade. Porto Alegre: EDIPUCRS, 2006. 
PAGNI, Pedro Ângelo. Dimensão Estética, linguagem e comunicação na experiência educativa: divergências entre Dewey e Adorno. Educação e Filosofia. Uberlândia, v. (23), n.(46), p. (169-188), jul./dez.2007.

VÁSQUEZ, Adolfo Sanchez. Ética e estética. Rio de Janeiro: Civilização Brasileira, 1999.

Submetido em julbo de 2020

Aprovado em novembro de 2020

\section{Informações do(a)(s) autor(a)(es)}

Maurício Inácio dos Santos

Fundação Presidente Antônio Carlos (Unipac). Lambari/MG - Brasil

E-mail:prof.mauricio.i.s@hotmail.com

ORCID: https://orcid.org/0000-0002-3111-4735

Link Lattes: http://lattes.cnpq.br/2223470684274418

Carlos Betlinski

Universidade Federal de Lavras - UFLA. Lavras/MG - Brasil

E-mail: carlosbetlinski@ufla.br

ORCID: https://orcid.org/0000-0003-1747-466X

Link Lattes: http:/ lattes.cnpq.br/3304007454034876 